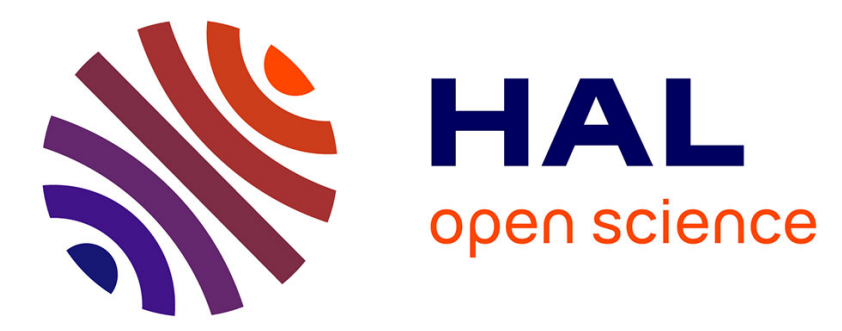

\title{
Photodynamic therapy for actinic keratosis: Is the European consensus protocol for daylight PDT superior to conventional protocol for Aktilite CL 128 PDT?
}

Anne-Sophie Vignion-Dewalle, Grégory Baert, Elise Thecua, Claire Vicentini, Laurent Mortier, Serge Mordon

\section{- To cite this version:}

Anne-Sophie Vignion-Dewalle, Grégory Baert, Elise Thecua, Claire Vicentini, Laurent Mortier, et al.. Photodynamic therapy for actinic keratosis: Is the European consensus protocol for daylight PDT superior to conventional protocol for Aktilite CL 128 PDT?. Journal of Photochemistry and Photobiology B: Biology, 2017. hal-01770583

\section{HAL Id: hal-01770583 \\ https://hal.science/hal-01770583}

Submitted on 19 Apr 2018

HAL is a multi-disciplinary open access archive for the deposit and dissemination of scientific research documents, whether they are published or not. The documents may come from teaching and research institutions in France or abroad, or from public or private research centers.
L'archive ouverte pluridisciplinaire HAL, est destinée au dépôt et à la diffusion de documents scientifiques de niveau recherche, publiés ou non, émanant des établissements d'enseignement et de recherche français ou étrangers, des laboratoires publics ou privés. 


\title{
Photodynamic therapy for actinic keratosis: Is the European consensus protocol for daylight PDT superior to conventional protocol for Aktilite CL 128 PDT?
}

\author{
Anne-Sophie Vignion-Dewalle ${ }^{1}$, Gregory Baert ${ }^{1}$, Elise Thecua ${ }^{1}$, Claire Vicentini ${ }^{1}$, Laurent \\ Mortier $^{1}$ and Serge Mordon ${ }^{1}$
}
${ }^{1}$ Univ. Lille, INSERM, CHU Lille, U1189 - ONCO-THAI - Image Assisted Laser Therapy for Oncology, F-59000 Lille, France

Corresponding author: Anne-Sophie Vignion-Dewalle

INSERM U1189 ONCO-THAI,

1, avenue Oscar Lambret,

F-59037 LILLE Cedex,

France

E-mail: anne-sophie.vignion@inserm.fr

\begin{abstract}
Background: Topical photodynamic therapy (PDT) is an established treatment modality for various dermato-oncologic conditions. In Europe, initially requiring irradiation with red light, PDT of actinic keratosis (AK) can now also be carried out with exposure to daylight that has been clinically proven to be as effective as and less painful than red light.

Objectives: In this paper, we propose a comparison between the conventional protocol for Aktilite CL 128 (red light source) PDT and the European consensus protocol for daylight PDT - with the exposure is assumed to be performed during either a clear sunny day or an overcast day — in the treatment of AK with methyl aminolevulinate through a mathematical modeling.

Method: This already published modeling that is based on an iterative procedure alternating determination of the local fluence rate and updating of the local optical properties enables to estimate the local damage induced by the therapy.

Results: The European consensus protocol for daylight PDT during a sunny day and an overcast day provides, on average, 6.50 and 1.79 times higher PDT local damages at the end
\end{abstract}


of the treatment than those obtained using the conventional protocol for Aktilite CL 128 PDT, respectively.

Conclusions: Results analysis shows that, even performed during an overcast day, the European consensus protocol for daylight PDT leads to higher PDT local damages than the efficient conventional protocol for Aktilite CL 128.

\section{Keywords: Photodynamic therapy; local damage comparison; mathematical modeling; red light; daylight; Aktilite CL 128.}

\section{Introduction}

Photodynamic therapy (PDT) is a cancer treatment combining a light of an appropriate wavelength, a photosensitizer (PS), and sufficient molecular oxygen to generate reactive oxygen species and destroy (pre-) malignant cells [1]. Over the last 15 years, topical PDT using 5-aminolevulinic acid (ALA) (ALA-PDT) or methyl aminolevulinate (MAL) (MALPDT) has proven to be successful in the treatment of various dermatological conditions including actinic keratoses (AK) [2-6]. Topical administration of ALA or MAL leads to the selective accumulation of the photosensitizer protoporphyrin IX (PpIX) in the AK lesions and subsequent light irradiation leads to the destruction of the lesions.

Red light irradiation with the Aktilite CL 128 lamp (Galderma SA, Lausanne, Switzerland) using a total light dose of $37 \mathrm{~J} / \mathrm{cm}^{2}$ after three hours of incubation with MAL, is a conventional protocol that is approved and widely used in Europe for the PDT treatment of AK. This protocol, referred to in this paper as the conventional protocol for Aktilite CL 128 PDT, has been demonstrated to be an effective treatment with similar efficacy and better cosmetic results compared with standard therapies [7]. However, due in particular to high pain scores reported by patient during the treatment [8] and high room occupancy for dermatologists, many other protocols for PDT involving either shorter incubation times [9], lower fluence rates [10], irradiation with other light sources [11]... have been proposed for dermatological PDT.

Among these alternative PDT protocols, several protocols involving exposure with daylight instead of irradiation with the Aktilite CL 128 lamp have been investigated over the last decade[11-16]. Most of these protocols involve an incubation with MAL for a maximum of 
30 minutes followed by a daylight exposure for between 1.5 and 2.5 hours. From an European consensus [14], using a two hours daylight exposure within 30 minutes after MAL application leads to a protocol, hereinafter referred to as the European consensus protocol for daylight PDT, as effective as and better tolerated by patients than the conventional protocol for Aktilite CL 128 PDT. The European consensus protocol for daylight PDT, more manageable in clinical practice than the conventional protocol for Aktilite CL 128 PDT [11], has been recently approved in Europe for the treatment of thin, non-hyperkeratotic AK [17]. Based on the two comparative clinical studies between a protocol for daylight PDT and the conventional protocol for Aktilite CL 128 PDT [11,16], we set the incubation time for the European consensus protocol for daylight PDT to 30 minutes.

In this paper, we propose to compare the efficiency of the conventional protocol for Aktilite CL 128 PDT (light source: Aktilite CL 128, incubation time: three hours, light dose: 37 $\mathrm{J} / \mathrm{cm}^{2}$ ) to the one of the European consensus protocol for daylight PDT (light source: daylight, incubation time: 30 minutes, treatment duration: two hours) through a mathematical modeling already published in our previous works $[18,19]$. Two weather conditions for the European consensus protocol for daylight PDT have been considered for this comparison: a clear sunny day and an overcast day. The mathematical modeling that involves a logistic model for both the biological clearance of PpIX and the conversion of MAL into PpIX and an analytic model for the PpIX photobleaching enables the local damage induced by the therapy to be estimated [19].

A detailed description of both the conventional protocol for Aktilite CL 128 PDT and the European consensus protocol for daylight PDT is presented in Section II while Section III describes the mathematical modeling enabling the quantification of the PDT local damage. The PDT local damages achieved by the conventional protocol for Aktilite CL 128 PDT, the European consensus protocol for daylight PDT during a sunny day and the European consensus protocol for daylight PDT during an overcast day are compared in Section IV. Based on the comparison results, some discussions and conclusions are drawn in Section V.

\section{The two topical PDT protocols considered in this paper}

Incubation time here refers to the time elapsed between the application of MAL cream and the beginning of the light irradiation. 


\section{A. The conventional protocol for Aktilite CL 128 PDT}

The Aktilite CL 128 lamp (Galderma SA, Lausanne, Switzerland) is the most widely used device system for topical PDT in Europe. Equipped with 128 light emitting diodes (LEDs) arranged in a $8 \times 16$ array, this lamp emits red light with a fluence rate of $70-100 \mathrm{~mW} / \mathrm{cm}^{2}$ (at a distance from $5 \mathrm{~cm}$ to $8 \mathrm{~cm}$ ) [20], a peak wavelength of $632 \mathrm{~nm} \mathrm{[21]} \mathrm{and} \mathrm{a} \mathrm{full} \mathrm{width} \mathrm{at} \mathrm{half}$ maximum (FWHM) of approximately $19 \mathrm{~nm}$ [21]. The fluence can be adjusted at the control panel of the lamp and the irradiation time is calculated automatically accordingly: for the 37 $\mathrm{J} / \mathrm{cm}^{2}$ as recommended for dermatological MAL-PDT, the irradiation time varies between 6 and 10 minutes. Moreover, with an irradiation field size of $8 \times 18 \mathrm{~cm}$, the Aktilite CL 128 lamp enables quite large fields to be treated.

Sequentially involving gentle curettage of the lesions, MAL cream application with occlusive dressing to each lesion and $5 \mathrm{~mm}$ of surrounding tissue for an incubation time of three hours, removal of excess MAL cream, positioning of the Aktilite CL 128 lamp head 5-8 cm over the area to be treated and irradiation with a total light dose of $37 \mathrm{~J} / \mathrm{cm}^{2}$, the so called conventional protocol for Aktilite CL 128 PDT has proven to be effective for the treatment of various skin malignancies [22-27] including actinic keratosis [7,28-30]. With similar response rates compared with standard therapies in the treatment for $\mathrm{AK}$, the conventional protocol for Aktilite CL 128 PDT has also demonstrated improved cosmetic outcomes [7,8].

\section{B. The European consensus protocol for daylight PDT}

Many studies on daylight PDT for the treatment of AK [11-16,31-34] have been published since the early work of Wiegell et al. [11].

As stated above, the fundamental difference between the protocols for daylight PDT and the protocols for Aktilite CL 128 PDT is the exposure to daylight in place of the red light provided by the Aktilite CL128 lamp.

Furthermore, most of the studies on daylight PDT report an incubation with MAL cream for a maximum of 30 minutes and no excess cream removal before exposure to daylight. The combination of these two factors involves, during all the procedure, an accumulation of PpIX greatly reduced compared to that of the protocols for Aktilite CL 128 PDT. In fact, the incubation time prior to the daylight exposure that is shorter than the usual three hours used 
for the protocols for Aktilite CL 128 PDT, results in a low initial PpIX accumulation. Thereafter, without excess cream removal and with a fluence rate lower than the one of the Aktilite CL 128 lamp, the protocols for daylight PDT allows for a balance between the development and the photodegradation of PpIX (the PpIX molecules are photoactivated / photodegraded as quickly they are formed) thus ensuring the maintain of a low PpIX accumulation.

Another difference between the protocols for daylight PDT and the protocols for Aktilite CL 128 PDT is the application of a chemical sunscreen to the treatment area to prevent sunburn. This sunscreen allowing wavelengths activating PpIX to pass through is usually applied before the gentle curettage of the lesions $[13,15,34]$.

Among the studies on daylight PDT, two randomized clinical trials each compared a protocol for daylight PDT with the conventional protocol for Aktilite CL 128 PDT [11,16]. With an exposure to daylight PDT of 2.5 hours and 2 hours for the first clinical trial [11] and the second one [16], respectively, the two involved protocols for daylight PDT (both with 30 minutes incubation time with MAL) have been demonstrated as effective as the conventional protocol for Aktilite CL 128 PDT. Furthermore, due to the above mentioned reduction in PpIX accumulation obtained with the protocols for daylight PDT, patients enrolled in these two trials reported less pain during the protocols for daylight PDT than during the conventional protocol for Aktilite CL 128 PDT $[11,16]$. This experience of a nearly pain-free treatment for patients has also been reported in other studies on daylight PDT [12-15,32-34]. Finally, with a shorter time of clinic attendance than the conventional protocol for Aktilite CL 128 PDT, the protocols for daylight PDT are more convenient for both patients and clinicians.

With a maximum of 30 minutes of MAL incubation and no excess cream removal before daylight exposure for 2 hours, the so called European consensus protocol for daylight PDT has been adopted from a European consensus in 2012 [14]. Based on the above mentioned randomized clinical trials $[11,16]$, we set the incubation time for the European consensus protocol for daylight PDT to 30 minutes.

In this study, the outdoor temperature was assumed to be sufficient for the PDT process to occur $[31,35]$ and thus no further consideration has been given to the temperature in this paper. 


\section{Mathematical modeling for topical PDT protocol}

\section{A. AK sample model}

To account for both the confinement of AKs to the epidermis and the usual $100 \mu \mathrm{m}$ thickness of epidermis [36], the simplified AK sample model consists of a $10 \mu \mathrm{m}$ wide and $100 \mu \mathrm{m}$ thick parallelepiped (Figure 1). The AK tissue is assumed homogeneous and its optical properties are set to the values reported in Garcia-Uribe et al. [37].

A primary planar beam with fluence rate $S_{0}$ is assumed to perpendicularly irradiate the surface of the AK sample model as illustrated in Figure 1.

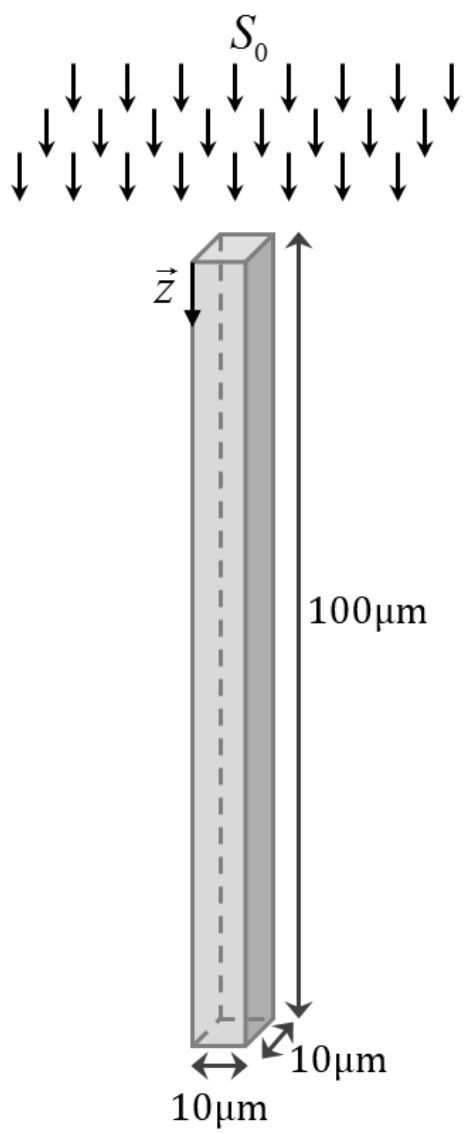

Figure 1: The AK sample model

\section{B. Models for the different fluence rates}

As depending on the weather conditions [31,38,39], the spectral fluence rate for the daylight is not unique. In this paper, two spectral fluence rates have been used: the first one 
corresponds to a clear sunny day (blue curve in Figure 2) while the second stands for an overcast day (cyan curve in Figure 2). These two spectral fluence rates were recorded in the study of O'Gorman et al. [39], who kindly provided them to us. The use of these two spectral fluence rates for the daylight aims to quantify the effect of the weather conditions on the PDT local damage.

Among the various spectral fluence rates for the Aktilite CL 128 lamp we have at our disposal, the one measured at a distance of $8 \mathrm{~cm}$ from the lamp by O'Gorman et al. [39] (red curve in Figure 2) was preferred. Indeed, recorded using the same measurement system as the two spectral fluence rates for daylight, this spectral fluence rate seems to be the most appropriate for a pertinent comparison.

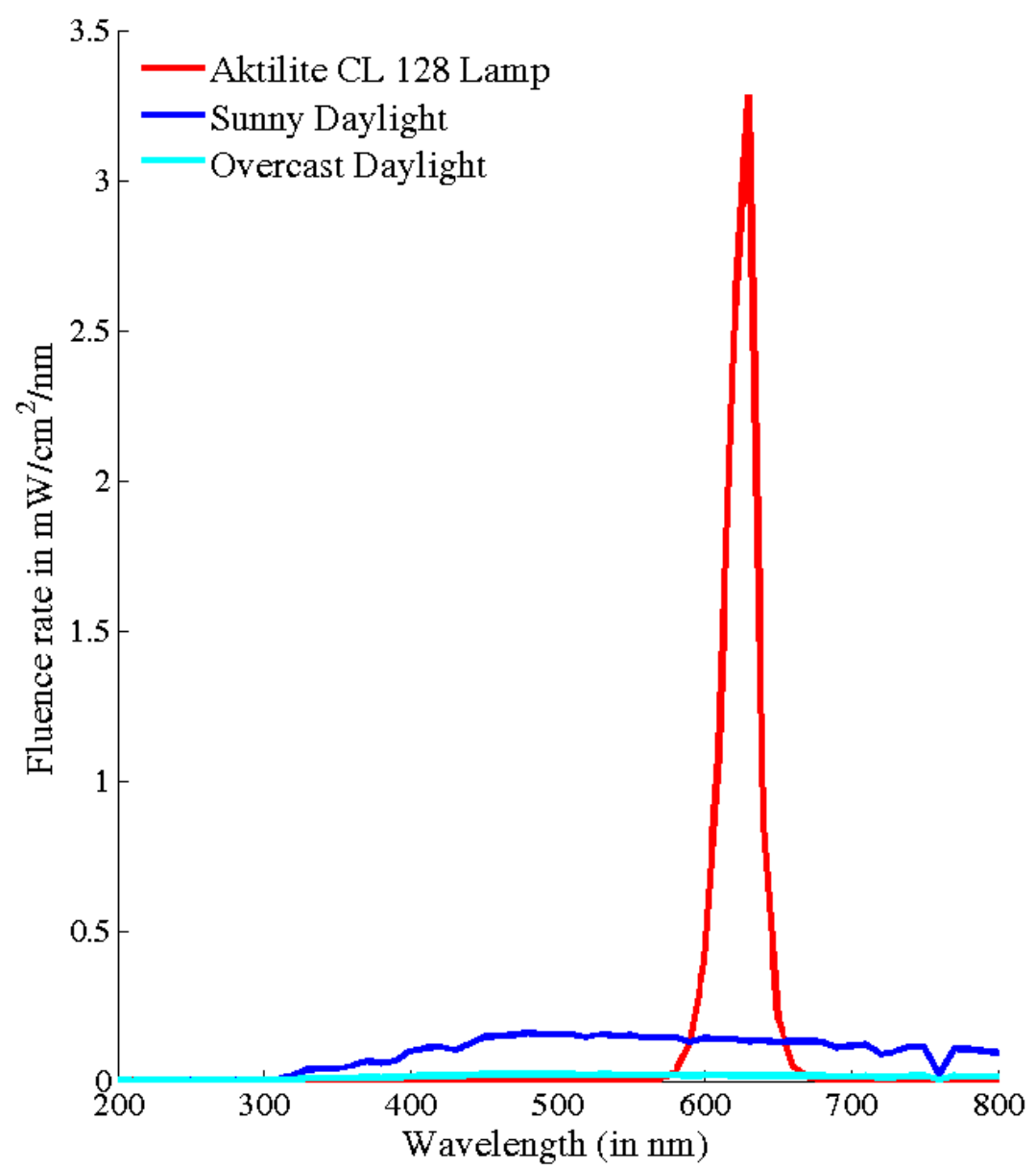

Figure 2: The spectral fluence rate for the Aktilite CL 128 lamp, the sunny daylight and the overcast daylight, respectively. All these three spectral fluence rates were provided by the authors of [39]. 


\section{Modeling of the PDT process}

The modeling method is the same as in our previously validated work [19] and therefore only outlines are referred to in this paper without further discussion.

Let the incubation start at time $t=0 s$ and let the light irradiation be performed during the time interval $\left[t_{\text {start }}, t_{\text {end }}\right]$ :

- $t_{\text {start }}=3$ hours and $t_{\text {end }}=t_{\text {start }}+\Delta t$ ( $\Delta t$ is the irradiation time necessary to achieve the recommended $37 \mathrm{~J} / \mathrm{cm}^{2}$ using the spectral fluence rate for the Aktilite CL 128 lamp depicted in Figure 2) for the conventional protocol for Aktilite CL 128 PDT,

- $t_{\text {start }}=0.5$ hours and $t_{\text {end }}=t_{\text {start }}+7200 \mathrm{~s}$ for the European consensus protocol for daylight PDT.

Based on our previous works [18,19], the modeling of the PDT process consists of two steps that are iteratively repeated: determination of the local fluence rate and updating of the PpIX absorption coefficient.

\section{Determination of the fluence rate}

The local total fluence rate at time $t$, depth $z$ and wavelength $\lambda$, denoted by $\varphi(t, z, \lambda)$, is given by equation $1[18,19,40]$ :

$$
\varphi(t, z, \lambda)= \begin{cases}0 & \text { for } t \notin\left[t_{\text {start }} ; t_{\text {end }}\right] \\
S_{0}\left\{\begin{array}{l}
\frac{b}{\sqrt{\mu_{\text {eff }}(t, z, \lambda)}} \exp \left[-\int_{0}^{z} \mu_{\text {eff }}(t, w, \lambda) d w\right] \\
+P(t, z, \lambda) \exp \left[-\int_{0}^{z} \mu_{t}^{\prime}(t, w, \lambda) d w\right]
\end{array}\right\} \text { for } t \in\left[t_{\text {start }} ; t_{\text {end }}\right]\end{cases}
$$

Where:

- The above defined $S_{0}$ is the spectral fluence rate of the primary planar broad beam,

- Due to the accumulation of PpIX in AK lesions, the total absorption coefficient, $\mu_{a}$, is the sum of the PpIX absorption coefficient, $\mu_{a, P p I X}$, and the actinic keratosis absorption 
coefficient, $\mu_{a, A K}$,

- The total transport coefficient, $\mu_{t}^{\prime}$, is the sum of the total absorption coefficient, $\mu_{a}$, and the actinic keratosis reduced scattering coefficient, $\mu_{s, A K}^{\prime}$,

- The effective attenuation coefficient, $\mu_{\text {eff }}$, is equal to $\sqrt{3 \mu_{a} \mu_{t}^{\prime}}$,

- The two parameters, $b$ and $P$, depending on both the optical properties of the actinic keratosis and the boundary conditions at the actinic keratosis surface, are computed as described in [40].

\section{Updating of the PpIX absorption coefficient}

The updating formula for the PpIX absorption coefficient in an unit volume, $V_{U}$, is expressed as follows (equation 2) [18,19]:

$$
\begin{aligned}
& \mu_{a, P p I X}(t+d t, z, \lambda)=\mu_{a, P p I X}(t, z, \lambda) \\
& +\frac{\varepsilon_{P p I X}(\lambda)}{\aleph V_{U}} \times L \times \exp (-\eta z) \times\left[\frac{1}{1+\exp (-k \times(t+d t-\tau))}-\frac{1}{1+\exp (-k \times(t-\tau))}\right] \\
& -d t \times \frac{\kappa}{\aleph V_{U}} \times \mu_{a, P p I X}(t, z, \lambda) \times \int_{\tilde{\lambda}}\left\{d t \times \gamma_{\tilde{\lambda}} \times \tilde{\lambda} \times \frac{\varphi(t, z, \tilde{\lambda})}{\eta c} \times V_{U} \times \mu_{a, P p I X}(t, z, \tilde{\lambda})\right\} d \tilde{\lambda}
\end{aligned}
$$

Where:

- $d t$ is the time increment,

- $\varepsilon_{P p I X}(\lambda)$ is the PpIX molar extinction coefficient for wavelength $\lambda$,

- $\aleph, \eta$ and $c$ are the Avogadro number $\left(6.022 \times 10^{23} / \mathrm{mol}\right)$, the Planck constant $\left(6.626 \times 10^{34} \mathrm{~J} \times \mathrm{s}\right)$ and the speed of light $\left(3 \times 10^{8} \mathrm{~m} / \mathrm{s}\right)$, respectively,

- $\quad L, k, \tau$ and $\eta$ are the parameters of the depth-dependent logistic growth related to both the biological clearance of PpIX and the conversion of 5-ALA into PpIX $\left(2^{\text {nd }}\right.$ term in the right hand side) [19],

- $\quad \kappa$ and $\gamma_{\tilde{\lambda}}$ are the bimolecular rate constant for the reaction of singlet oxygen with PpIX and the singlet oxygen quantum yield, respectively. These two parameters allow the photobleaching process to be analytically modeled ( $3^{\text {rd }}$ term in the right hand side) [19].

\section{Iterative procedure}

All the involved parameters were assigned to the values reported in our previous work and 
empirically determined in the literature [18,19] (Table 1). Assuming the initial distribution for the PpIX absorption coefficient reported in the last row in Table 1, equation 1 enables the local total fluence rate at time $0,\{\varphi(0, z, \lambda)\}_{z, \lambda}$, to be calculated. Applying equation 2 then yields the distribution for the PpIX absorption coefficient at time $d t,\left\{\mu_{a, P p I X}(d t, z, \lambda)\right\}_{z, \lambda}$, to be deduced. By iterating equations 1 and 2, all the PpIX absorption coefficients and local total fluence rates can be determined throughout the treatment.

\begin{tabular}{cc}
\hline Parameters & Value \\
\hline$d t$ & $1 \times 10^{-5} \mathrm{~s}$ \\
\hline$k$ & $2.93 \times 10^{-4} / \mathrm{s}$ \\
\hline$\tau$ & $1.01 \times 10^{4} \mathrm{~s}$ \\
\hline$\eta$ & $0.89 / \mathrm{mm}$ \\
\hline$L$ & $11.8 \mathrm{pmol} / \mathrm{ml} \times \aleph V_{U} \times[1+\exp (-k \times(3 \mathrm{~h}-\tau))]$ \\
\hline$\gamma_{\lambda}$ & $5.3 \times 10^{9} 1 / \mathrm{mol} / \mathrm{s}$ \\
\hline$\mu_{a, P p I X}(0, z, \lambda)$ & 0.56 \\
\hline
\end{tabular}

Table 1: Specification of the model parameters from [19]

\section{Quantification of the PDT local damage}

The integral in the last part of the right hand side of equation 2 represents the number of singlet oxygen molecules generated during the time interval $] ; t+d t]$ in an unit volume, $V_{U}$, located at depth $z$ in the AK sample model when the PpIX molecules, excited by absorption of photons, return to the ground state. Summing this integral over the time intervals ]$\left.\left.\left.\left.\left._{\text {start }} ; t_{\text {start }}+d t\right],\right] t_{\text {start }}+d t ; t_{\text {start }}+2 \times d t\right], \ldots,\right] t_{\text {start }}+(i-1) \times d t ; t_{\text {start }}+i \times d t\right]$ provides the total cumulative singlet oxygen molecules produced during the time interval $\left.] t_{\text {start }} ; t_{\text {start }}+i \times d t\right]$. From several studies on PDT [40,41], this cumulative quantity enables the quantification of the PDT local damage, $D$, over time (equation 3 ). 


$$
D\left(t_{\text {start }}+i \times d t, z\right)=\sum_{j=0}^{i-1}\left[\int_{\tilde{\lambda}}\left\{\begin{array}{l}
d t \times \gamma_{\tilde{\lambda}} \times \tilde{\lambda} \times \frac{\varphi\left(t_{\text {start }}+j \times d t, z, \tilde{\lambda}\right)}{\eta c} \times V_{U} \\
\times \mu_{a, P \text { PIX }}\left(t_{\text {start }}+j \times d t, z, \tilde{\lambda}\right)
\end{array}\right\} d \tilde{\lambda}\right]
$$

\section{Results}

\section{A. Comparison in terms of effective fluence}

Given the spectral fluence rate for the Aktilite CL 128 lamp (Figure 2), several parameters have been computed (Table 2). First, from the integration of this spectrum over wavelength, the fluence rate has been estimated to be $85.39 \mathrm{~mW} / \mathrm{cm}^{2}$ that is consistent with the abovementioned $70-100 \mathrm{~mW} / \mathrm{cm}^{2}$ range provided by the manufacturer. By considering this fluence rate, the fluence of $37 \mathrm{~J} / \mathrm{cm}^{2}$ of the conventional protocol for Aktilite CL 128 PDT is achieved using an irradiation time of 433.3 seconds (Table 2). Moreover, weighting the spectral fluence rate with the normalized absorption spectrum for PpIX, which is derived from data measured by the Research Center for Automatic Control of Nancy (CRAN) (Figure 3.a), enables the effective or PpIX-weighted spectral fluence rate to be obtained (Figure 3.a) and the effective fluence rate to be deducted by integration over wavelength (approximately, $1.44 \mathrm{~mW} / \mathrm{cm}^{2}$ ) [11,39] (Table 2). Multiplying the effective fluence rate by the above determined irradiation time of 433.3 seconds leads to an effective fluence of $0.63 \mathrm{~J} / \mathrm{cm}^{2}$ for the conventional protocol for Aktilite CL 128 PDT.

Similar computations have been carried out for the sunny daylight spectral fluence rate and the overcast daylight spectral fluence rate (Figure 2). The integration over wavelength of these two spectral fluence rates yields fluence rates of $55.2 \mathrm{~mW} / \mathrm{cm}^{2}$ and $7.75 \mathrm{~mW} / \mathrm{cm}^{2}$ for the sunny daylight and the overcast daylight, respectively (Table 2). The effective or PpIXweighted spectral fluence rate for the sunny daylight (respectively, the overcast daylight), which was obtained by weighting the spectral for the sunny daylight fluence rate (respectively, the overcast daylight fluence rate) with the normalized absorption spectrum for PpIX, yields, when integrated over wavelength, an effective fluence rate of $5.11 \mathrm{~mW} / \mathrm{cm}^{2}$ (respectively, $0.80 \mathrm{~mW} / \mathrm{cm}^{2}$ ) for the sunny daylight (respectively, the overcast daylight) (Table 2, Figure 3.b and 3.c). Using an exposure of 2 hours as required with the European consensus protocol for daylight PDT, the sunny daylight fluence rate (respectively, the effective sunny daylight fluence rate) leads to a fluence of $397.44 \mathrm{~J} / \mathrm{cm}^{2}$ (respectively, an 
effective fluence of $36.79 \mathrm{~J} / \mathrm{cm}^{2}$ ) while the overcast daylight fluence rate (respectively, the effective overcast daylight fluence rate) provides a fluence of $55.8 \mathrm{~J} / \mathrm{cm}^{2}$ (respectively, an effective fluence of $5.76 \mathrm{~J} / \mathrm{cm}^{2}$ ).

From these computations performed using a homemade software available online [42], the effective fluence achieved using the European consensus protocol for daylight PDT during a sunny day is 58.40 and 6.40 times higher than those achieved using the conventional protocol for Aktilite CL 128 PDT and the European consensus protocol for daylight PDT during an overcast day, respectively. The effective fluence obtained using the European consensus protocol for daylight PDT during an overcast day is also - although to a lesser extent than the European consensus protocol for daylight PDT during a sunny day — higher (9.13 times higher) than that obtained using the conventional protocol for Aktilite CL 128.

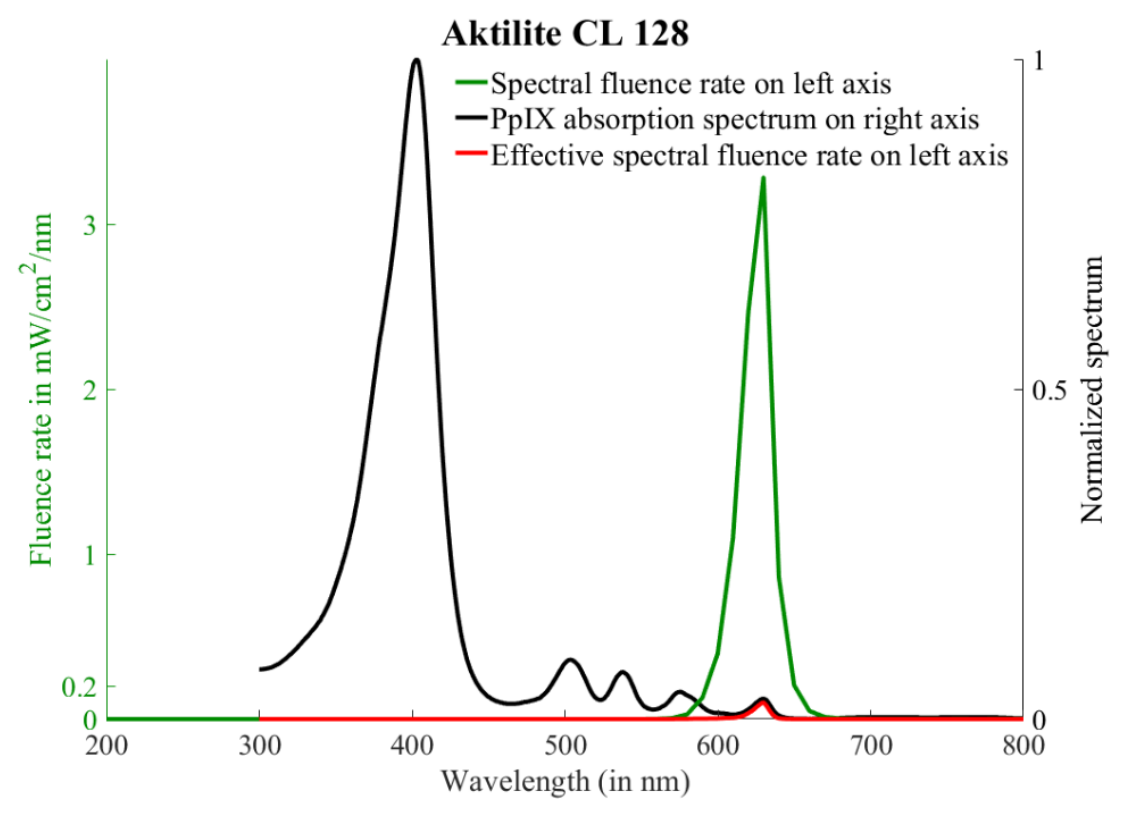

a 


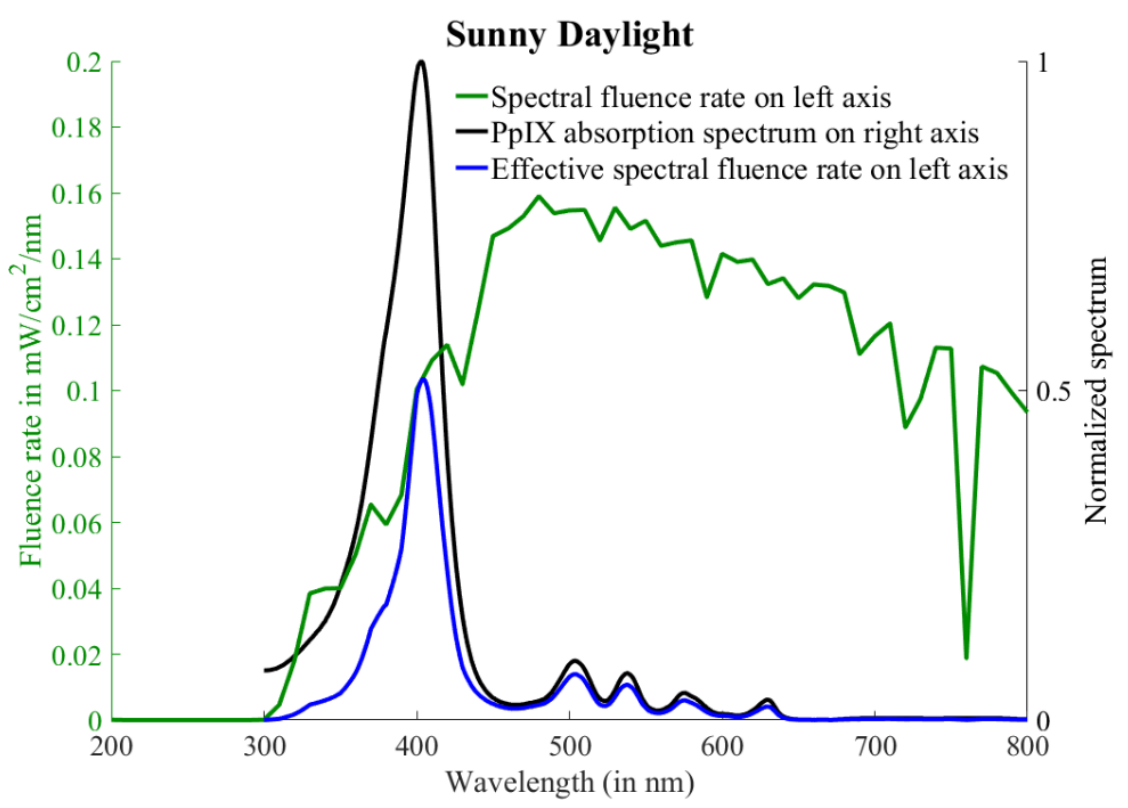

b

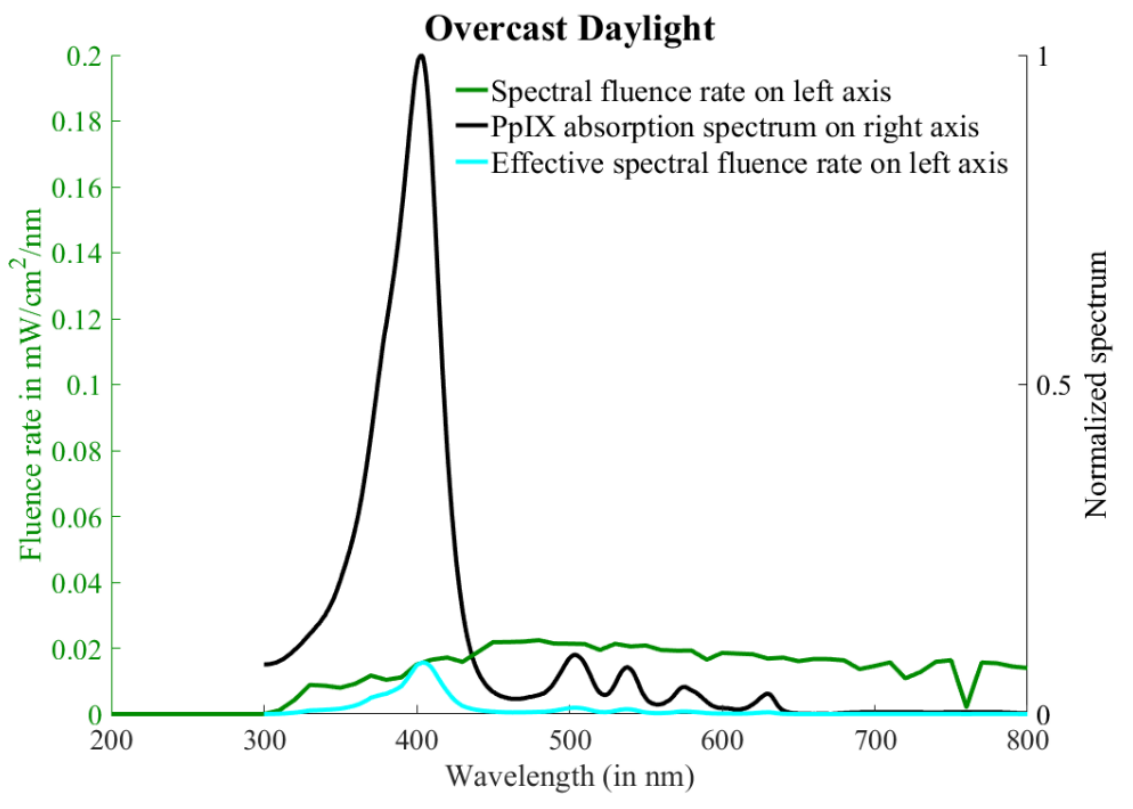

c

Figure 3: The spectral fluence rate (green curves) and the effective spectral fluence rate (red curve in a), blue curve in b) and cyan curve in c)) for a) the Aktilite CL 128 lamp at a distance of $8 \mathrm{~cm}$ from the lamp, b) the sunny daylight and c) the overcast daylight are scaled according to the left axis while the normalized absorption spectrum for PpIX (black curve) is plotted according to the right axis (Note: left axes in (b) and (c) are identically scaled whereas a different scale is applied for (a) due to its much higher amplitude). All the three spectral fluence rates were provided by the authors of [39].

Light source

$\begin{array}{lll}\text { Aktilite } & \text { Sunny } & \text { Overcast } \\ \text { CL128 } & \text { daylight } & \text { daylight }\end{array}$




\begin{tabular}{cccc}
\hline & lamp & & \\
\hline Incubation time in $\mathrm{h}$ & 3 & 0.5 & 0.5 \\
\hline Irradiation time in $\mathrm{s}$ & 433.3 & 7200 & 7200 \\
\hline Fluence rate in $\mathrm{mW} / \mathrm{cm}^{2}$ & 85.39 & 55.2 & 7.75 \\
\hline $\begin{array}{c}\text { Fluence in } \mathrm{J} / \mathrm{cm}^{2} \text { (product of the irradiation time in } \\
\mathrm{s} \text { and the fluence rate in W/cm }{ }^{2} \text { ) }\end{array}$ & 37 & 397.44 & 55.8 \\
\hline $\begin{array}{c}\text { Effective or PpIX-weighted fluence rate in } \\
\mathrm{mW} / \mathrm{cm}^{2}\end{array}$ & 1.44 & 5.11 & 0.80 \\
\hline $\begin{array}{c}\text { Effective fluence in } \mathrm{J} / \mathrm{cm}^{2} \text { (product of the } \\
\text { irradiation time in } \mathrm{s} \text { and the effective fluence rate } \\
\text { in W/cm }{ }^{2} \text { ) }\end{array}$ & 0.63 & 36.79 & 5.75 \\
\hline
\end{tabular}

Table 2: Standard (row 4) and effective (row 6) fluence rates for the Aktilite CL128 lamp (second column), the sunny daylight (third column) and the overcast daylight (fourth column) computed from the spectral fluence rate provided by [39]. The irradiation times used in this paper (row 3) and the corresponding standard and effective fluences are also indicated (rows 5 and 7).

\section{B. Comparison in terms of photodynamic dose}

All the computations were performed using a Matlab ${ }^{\mathrm{TM}}$ program on a standard personal computer (Intel Xeon CPU E3-1240 V2 3.40 GHz-8Go of RAM-Windows 764 bits).

The PDT local damages obtained using the conventional protocol for Aktilite CL 128 PDT, the European consensus protocol for daylight PDT during a sunny day and the European consensus protocol for daylight PDT during an overcast day are displayed as a function of depth in Figure 4 and as a function of time in Figure 5. 


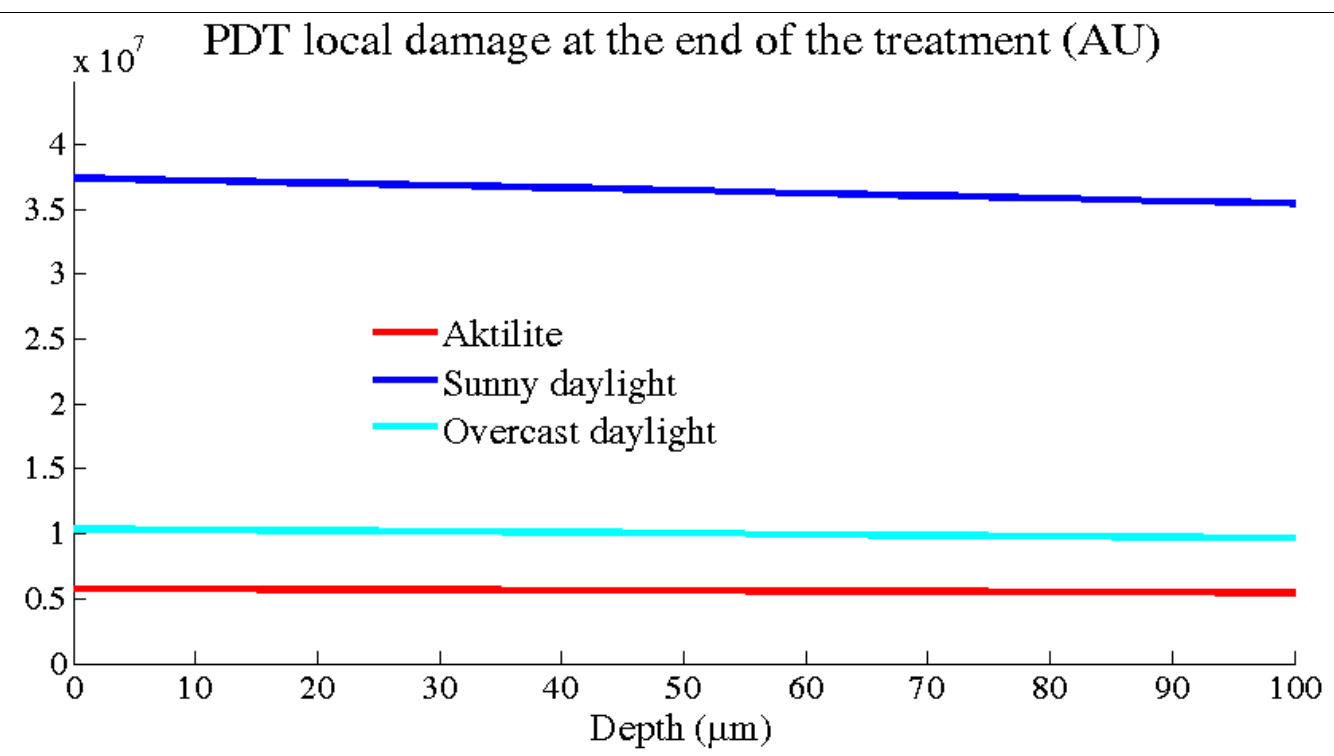

Figure 4: Evolution in depth of the PDT local damage achieved at the end of the treatment using the conventional protocol for Aktilite CL 128 PDT (red curve), the European consensus protocol for daylight PDT during a sunny day (blue curve) and the European consensus protocol for daylight PDT during an overcast day (cyan curve).

From Figure 4, whatever the depth position in the AK sample model (Figure 1), the PDT local damage achieved at the end of the treatment using the European consensus protocol for daylight PDT during a sunny day is on average about 6.50 and 3.63 times higher than those achieved at the end of the treatment using the conventional protocol for Aktilite CL 128 PDT and using the European consensus protocol for daylight PDT during an overcast day, respectively. The ratio between the PDT local damage obtained using the European consensus protocol for daylight PDT during an overcast day and the one obtained using the conventional protocol for Aktilite CL 128 PDT is approximately 1.80 at $0 \mu \mathrm{m}$ depth and 1.77 at $100 \mu \mathrm{m}$ depth. 


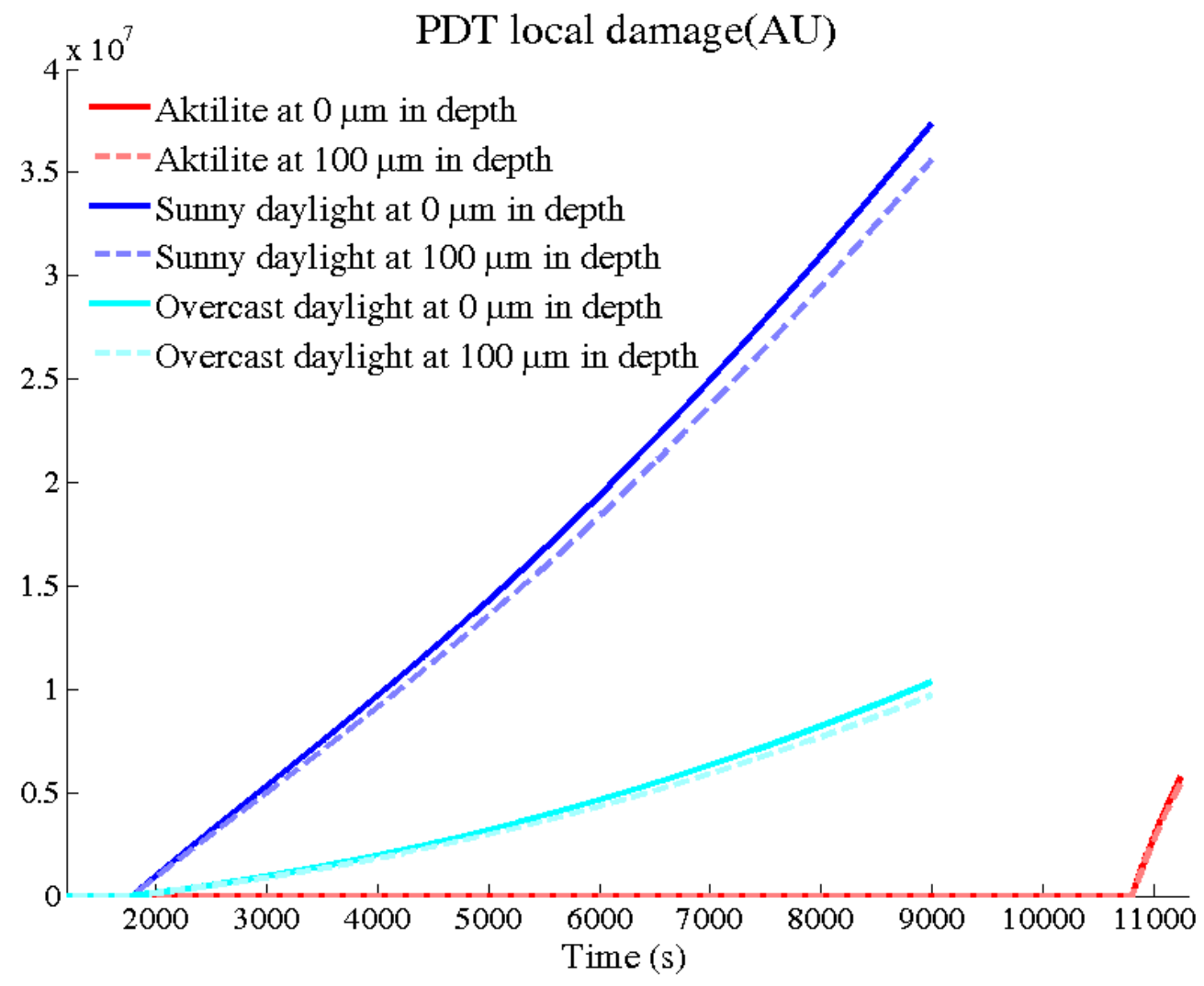

Figure 5: Evolution in time of the PDT local damage achieved using the conventional protocol for Aktilite CL 128 PDT (red curves), the European consensus protocol for daylight PDT during a sunny day (blue curves) and the European consensus protocol for daylight PDT during an overcast day (cyan curves). The bright solid curves (respectively, light dashed curves) represent the PDT local damages at $0 \mu \mathrm{m}$ (respectively, at $100 \mu \mathrm{m}$ ) in depth in AK.

From Figure 5, for the European consensus protocol for daylight PDT, the shape of the time courses of the PDT local damage tends to demonstrate an exponential trend (blue and cyan curves in Figure 5) while that for the conventional protocol for Aktilite CL 128 PDT suggests a very slight logarithmic trend (red curves). This results that, at least over the considered time intervals, the PDT local damage produced using the conventional protocol for Aktilite CL 128 PDT increases in time much faster than those produced using the European consensus protocol for daylight PDT (Figure 5).

\section{Comparison in terms of number of PpIX molecules}

The evolution of the number of PpIX molecules present in an unit volume, $V_{U}$, at time $t$ and depth $z$, deduced from equation 4 , is illustrated for the conventional protocol for Aktilite CL 
128 PDT, the European consensus protocol for daylight PDT during a sunny day and the European consensus protocol for daylight PDT during an overcast day in Figure 6.

$$
M_{P p I X}(t, z)=\mu_{a, P p I X}(t, z, \lambda) \times \frac{\aleph V_{U}}{\varepsilon_{P p I X}(\lambda)}
$$

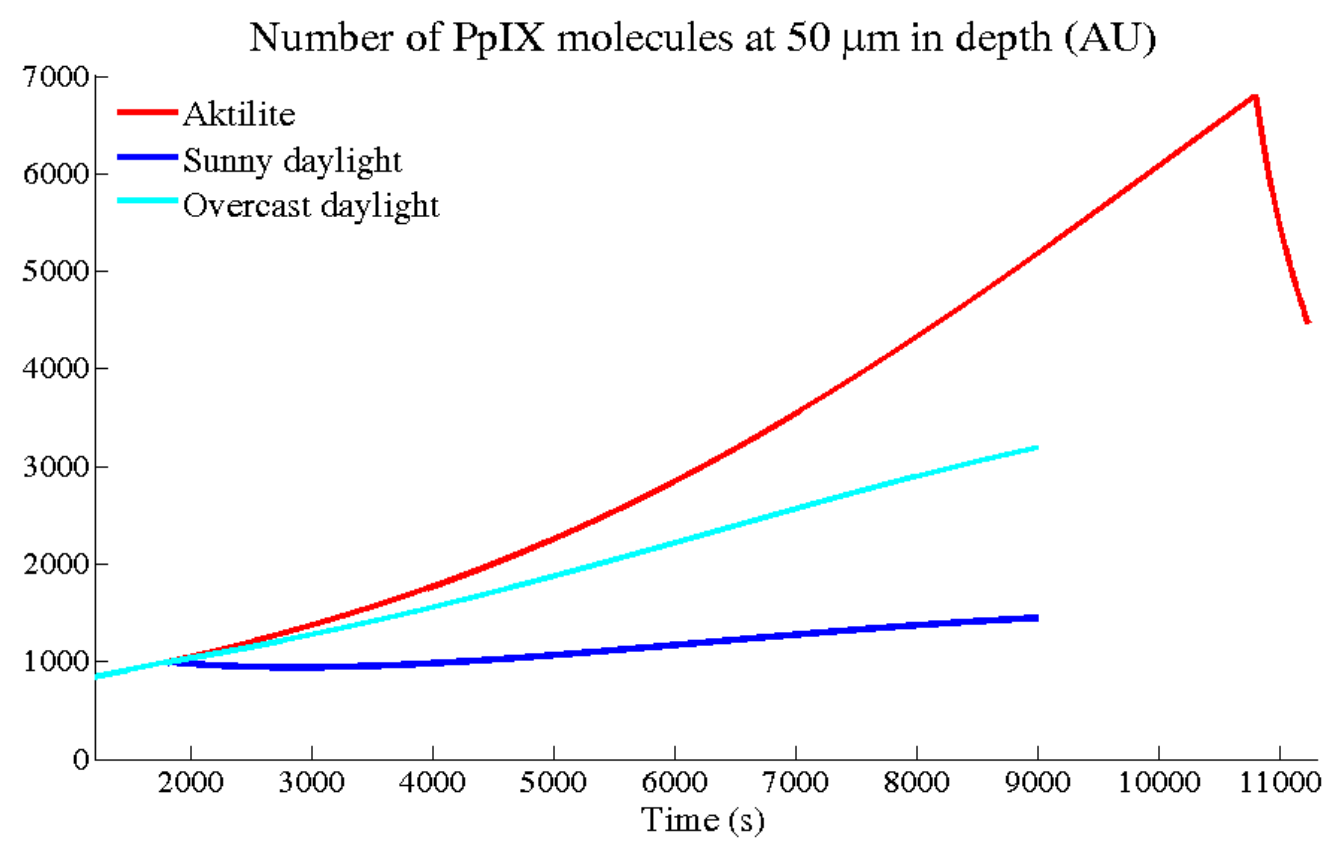

Figure 6: Evolution in time of the number of PpIX molecules present at $50 \mu \mathrm{m}$ in depth in $\mathrm{AK}$ using the conventional protocol for Aktilite CL 128 PDT (red curve), the European consensus protocol for daylight PDT during a sunny day (blue curve) and the European consensus protocol for daylight PDT during an overcast day (cyan curve).

From Figure 6, regarding the conventional protocol for Aktilite CL 128 PDT, the irradiation (starting at time $=10800 \mathrm{~s}$ ) leads to a mean percent drop of $35.24 \%$ in the number of PpIX molecules while the number of PpIX molecules corresponding to the European consensus protocol for daylight PDT during an overcast day continues to increase even after the beginning of irradiation (occurring at time 1800 seconds). For the European consensus protocol for daylight PDT during a sunny day, the irradiation results, in terms of the number of PpIX molecules, in a transient slight decrease followed by a further controlled increase.

Furthermore, an important number of PpIX molecules is still present at the end of the irradiation for the conventional protocol for Aktilite CL 128 PDT and the European consensus protocol for daylight PDT during an overcast day (Figure 6). With regard to the European consensus protocol for daylight PDT during a sunny day, the number of PpIX molecules 
present at the end of the irradiation is slightly higher than that at the beginning of irradiation.

\section{Discussion}

In this paper, a comparison between the two most widely used MAL-PDT protocols in Europe for the treatment of actinic keratosis (AK) is performed using a mathematical modeling of the PDT process:

- The conventional protocol for Aktilite CL 128 PDT (light source: Aktilite CL 128, incubation time: three hours, light dose: $37 \mathrm{~J} / \mathrm{cm}^{2}$ ) [7,8,29],

- The European consensus protocol for daylight PDT (light source: daylight, incubation time: 30 minutes, treatment duration: two hours) [14].

Two weather conditions for the European consensus protocol for daylight PDT have been considered for this comparison: a clear sunny day and an overcast day. The spectral fluence rates for the Aktilite CL 128, the clear sunny daylight and the overcast daylight have been provided by the authors of O'Gorman et al. [39] (Figure 2).

The comparison is performed using an AK sample model consisting of a $100 \mu \mathrm{m}$ thick parallelepiped (Figure 1) and a recently published modeling of the PDT process iteratively alternating determination of the fluence rate and updating of the optical properties $[18,19]$. The determination of the fluence rate involves solving the one-dimensional diffusion equation (equation 1, [18,19]) while the updating of the optical properties takes the biological clearance of PpIX, the conversion of MAL into PpIX and the PpIX photobleaching into account (equation 2, [19]). All the parameters involved in equations 1 and 2 are set to published empirical values, which were obtained with PpIX and with either normal human epidermis or AK (Table 1, [18]). The updating formula (equation 2) explicitly provides the number of singlet oxygen molecules produced at each iteration (integral in the right hand side). Cumulating this number over the irradiation time enables the quantification of the PDT local damage (equation 3, [18,19]).

Applying to the conventional protocol for Aktilite CL 128 PDT, to the European consensus protocol for daylight PDT during a sunny day and to the European consensus protocol for daylight PDT during an overcast day, the model allows evaluation and comparison of their performance in terms of the PDT local damage. A comparison has also been performed in terms of effective or PpIX-weighted fluence. 
From the results, regardless the two weather conditions considered in this study, the European consensus protocol for daylight PDT is more efficient in terms of both effective fluence and PDT local damage than the conventional protocol for Aktilite CL 128 PDT. First, this finding underlines the relevance of the European consensus protocol for daylight PDT, even when performed during an overcast day. Then this finding supports the non-inferiority in efficacy of the European consensus protocol for daylight PDT compared to the conventional protocol for Aktilite CL 128 PDT that has been demonstrated by a clinical trial, including all weather conditions except rain or cold [16]. This finding also suggests that, although a minimum effective fluence of $8 \mathrm{~J} / \mathrm{cm}^{2}$ is recommended with daylight PDT to result in an effective treatment of $\mathrm{AK}[12,31]$, the effective fluence of $5.75 \mathrm{~J} / \mathrm{cm}^{2}$ related to the overcast day considered in this study (Table 2), is sufficient for the European consensus protocol for daylight PDT to perform better than the efficient conventional protocol for Aktilite CL 128 PDT. Finally, based on the well-known efficiency of the conventional protocol for Aktilite CL 128 PDT, this finding could reflect a potential over-treatment of the lesions when using the European consensus protocol for daylight PDT during a sunny day but also during an overcast day.

As already mentioned in many studies on daylight PDT [12,13,15,31,39] and as evidenced by the above mentioned values, the effective fluence varies depending on weather conditions. This dependence on weather conditions is also evident here in terms of the PDT local damage: the better the weather conditions, the more efficient is the European consensus protocol for daylight PDT. Nonetheless, based on the studies of Wiegell et al. [12,31] and O'Gorman et al [39] that have found no association between response rate and effective fluence in patients who received an effective fluence with daylight PDT higher than $8 \mathrm{~J} / \mathrm{cm}^{2}$ and $3.2 \mathrm{~J} / \mathrm{cm}^{2}$, respectively, a sunny day is not necessarily required for the European consensus protocol for daylight PDT to be effective (an overcast daylight may be sufficient for the European consensus protocol for daylight PDT to destroy any cancer cells). This has also been highlighted by Rubel et al. [16], which have reported that, although patients received variable effective fluences during the European consensus protocol for daylight PDT, no correlation to efficacy was found. These clinical results with similar response rates whatever the weather conditions (except rainy or cold conditions) tend to support the above suggested hypothesis of overtreatment of the lesions by the European consensus protocol for daylight PDT. 
The information provided by the ratios between the effective fluences is consistent with that provided by the ratios between the PDT local damages. In fact, if a ratio between two considered effective fluences is higher than 1 , then the ratio between the two corresponding PDT local damages is also higher than 1. Nonetheless, the ratios between the effective fluences are always higher than those between the PDT local damages. This is explained, to a large extent, by the fact that the effective fluence is computed using the normalized absorption spectrum for PpIX (Figure 3) whereas the PDT local damages involves the "actual" absorption spectrum for PpIX. With an incubation time longer than that for the European consensus protocol for daylight PDT, the conventional protocol for Aktilite CL 128 PDT leads to a higher initial PpIX accumulation (Figure 6) and subsequently to a higher initial absorption spectrum for PpIX. This in turn allows to partially offset the higher effective fluence rate for the European consensus protocol for daylight PDT in the iterative calculation of the PDT local damage (equations 1-3). In contrast, as the effective fluence is computed from the normalized PpIX absorption spectrum, no such offset is present and thus the information provided by the effective fluence might not be sufficient to predict the result of the MAL-PDT procedure. The PDT local damage, as defined in this paper, may therefore be a more appropriate predictor...

Regarding the evolution in time of the PDT local damage (Figure 5), with an effective fluence rate about 3.55 times lower than that of the European consensus protocol for daylight PDT during a sunny day (Table 2), the conventional protocol for Aktilite CL 128 PDT, however, leads to a higher increase rate for the PDT local damage. This results from the above mentioned longer incubation time and subsequent higher initial PpIX absorption coefficient for the conventional protocol for Aktilite CL 128 PDT compared to the European consensus protocol for daylight PDT, leading to a higher initial photons absorption efficiency (equations 1-3).

From Figure 6, the beginning of the irradiation is clearly identifiable for the conventional protocol for Aktilite CL 128 PDT with a more than 30 percent drop in the number of PpIX molecules resulting from the above mentioned high initial photons absorption efficiency. On the contrary, the steady growth curve observed for the European consensus protocol for daylight PDT during an overcast day makes the identification of the beginning of the irradiation impossible: the $0.80 \mathrm{~mW} / \mathrm{cm}^{2}$ effective fluence rate combined with a low initial PpIX accumulation do not allow a photobleaching of the PpIX molecules important enough to 
outweigh the conversion of MAL into PpIX. Regarding the European consensus protocol for daylight PDT during a sunny day, despite the low initial PpIX accumulation, the 5.11 $\mathrm{mW} / \mathrm{cm}^{2}$ effective fluence rate appears to be appropriate for maintaining approximately constant the number of PpIX molecules.

Consideration also needs to be given to the important number of PpIX molecules still present at the end of the conventional protocol for Aktilite CL 128 PDT (Figure 6). This important number tends to demonstrate that the incubation time or the cream concentration in MAL for this protocol could be reduced [43]. This observation can be extended to the European consensus protocol for daylight PDT during an overcast day...

The overall results emphasize the need to refine the parameters of both the conventional protocol for Aktilite CL 128 PDT and the European consensus protocol for daylight PDT. This refinement (reduction of the incubation time, reduction of the irradiation time...) would allow for a similar efficiency but an improved tolerability and a more manageable clinical practice.

Only two weather conditions for the European consensus protocol for daylight PDT have been studied in this paper. These two weather conditions have been chosen because their spectral fluence rates discussed in the study of O'Gorman et al. [39] have been kindly provided by the authors. Any other weather condition with an available spectral fluence rate could obviously be investigated using the same mathematical modeling... The subsequent results will either support the above suggested hypothesis of overtreatment of the lesions by the European consensus protocol for daylight PDT, or will allow to estimate the PDT local damage at which the treatment becomes effective.

In this study, the temperature was, as above mentioned, assumed to be at least $10^{\circ} \mathrm{C}$ so that the PDT process to occur [31,35]. If this is not the case, or if it's raining or windy, a greenhouse may be used [44]. However, the spectral fluence rate of the daylight is modified by the filtering effect of the greenhouse glass, and the mathematical modeling proposed in this paper could be used to quantify this filtering effect in terms of the PDT local damage. Another solution to get rid of this dependence on the weather conditions, geographical location, seasons..., is to use a light source with a spectral fluence rate close to that of daylight $[39,44]$; a comparative study of these light sources for "indoor" daylight PDT could also be performed in terms of the PDT local damage as defined in this paper. 


\section{Conclusion}

In this paper, we have compared the conventional protocol for Aktilite CL 128 PDT (light source: Aktilite CL 128, incubation time: three hours, light dose: $37 \mathrm{~J} / \mathrm{cm}^{2}$ ) with the European consensus protocol for daylight PDT (light source: daylight, incubation time: 30 minutes, treatment duration: two hours). This comparison performed in terms of the effective fluence and the PDT local damage tends to demonstrate, whatever the two weather conditions considered for this comparison (i.e., a clear sunny day and an overcast day) the European consensus protocol for daylight PDT perform better than the conventional protocol for Aktilite CL 128 PDT. 


\section{Acknowledgements}

The authors would like to thank M. Manley from the Department of Medical Physics and Clinical Engineering, Saint Vincent's University Hospital, Dublin, Ireland, UK, for providing the spectral fluence rates for 1) the Aktilite CL128 lamp (Galderma SA, Lausanne, Switzerland), 2) the daylight on a clear sunny day and 3) the daylight on an overcast day. 
1 Plaetzer K., Krammer B., Berlanda J., Berr F., and Kiesslich T., Photophysics and photochemistry of photodynamic therapy: fundamental aspects., Lasers Med Sci., 24, 2, 259, 268, 2009.

2 Bissonette R., Bergeron A., and Liu Y., Large surface photodynamic therapy with aminolevulinic acid: treatment of actinic keratoses and beyond., J Drugs Dermatol., 3, 1 Suppl, S26, S31, 2004.

3 Braathen LR., Szeimies RM., Basset-Seguin N., Bissonette R., Foley P., Pariser D., Roelandts R., Wennberg AM., and Morton CA., Guidelines on the use of photodynamic therapy for nonmelanoma skin cancer: an international consensus., J Am Acad Dermatol., 56, 1, 125, 143, 2007.

4 Morton CA., McKenna KE., and Rhodes LE., Guidelines for topical photodynamic therapy: update., Br J Dermatol., 159, 6, 1245, 1266, 2008.

5 Morton C., Szeimies RM., Sidoroff A., Wennberg AM., Basset-Seguin N., CalzavaraPinton P., Gilaberte Y., Hofbauer G., Hunger R., Karrer S., Lehmann P., Piaserico S., Ulrich C., and Braathen L., European Dermatology Forum Guidelines on topical photodynamic therapy., Eur J Dermatol., 25, 4, 296, 311, 2015.

6 Wiegell SR., Update on photodynamic treatment for actinic keratosis., Curr Probl Dermatol., 46, 122, 128, 2015.

7 Morton C., Campbell S., Gupta G., Keohane S., Lear J., Zaki I., Walton S., Kerrouche N., Thomas G., and Soto P., Intraindividual, right-left comparison of topical methyl aminolaevulinate-photodynamic therapy and cryotherapy in subjects with actinic keratoses: a multicentre, randomized controlled study., Br J Dermatol., 155, 5, 1029, 1036, 2006.

8 Tyrrell J., Campbell SM., and Curnow A., The effect of air cooling pain relief on protoporphyrin IX photobleaching and clinical efficacy during dermatological photodynamic therapy., J Photochem Photobiol B., 103, 1, 1, 7, 2011.

9 Braathen LR., Paredes BE., Saksela O., Fritsch C., Gardlo K., Morken T., Frolich KW., Warloe T., Soler AM., and Ros AM., Short incubation with methyl aminolevulinate for photodynamic therapy of actinic keratoses., J Eur Acad Dermatol Venereol., 23, 5, 550, 555, 2009.

10 Apalla Z., Sotiriou E., Panagiotidou D., Lefaki I., Goussi C., and Ioannides D., The impact of different fluence rates on pain and clinical outcome in patients with actinic keratoses treated with photodynamic therapy., Photodermatol Photoimmunol Photomed, 27, 4, 181, 185, 2011.

11 Wiegell SR., Haedersdal M., Philipsen PA., Eriksen P., Enk CD., and Wulf HC., Continuous activation of PpIX by daylight is as effective as and less painful than conventional photodynamic therapy for actinic keratoses; a randomized, controlled, single-blinded study., Br J Dermatol., 158, 4, 740, 746, 2008. 
12 Wiegell SR., Haedersdal M., Eriksen P., and Wulf HC., Photodynamic therapy of actinic keratoses with $8 \%$ and $16 \%$ methyl aminolaevulinate and home-based daylight exposure: a double-blinded randomized clinical trial., Br J Dermatol., 160, 6, 1308, $1314,2009$.

13 Wiegell SR., Fabricius S., Stender IM., Berne B., Kroon S., Andersen BL., Mork C., Sandberg C, Jemec GB., Mogensen M., Brocks KM., Philipsen PA., Heydenreich J., Haedersdal M., and Wulf HC., A randomized, multicentre study of directed daylight exposure times of $1 \frac{1 / 2}{2}$ vs. $2 \frac{1}{2} \mathrm{~h}$ in daylight-mediated photodynamic therapy with methyl aminolaevulinate in patients with multiple thin actinic keratoses of the face and scalp., Br J Dermatol., 164, 5, 1083, 1090, 2011.

14 Wiegell SR., Wulf HC., Szeimies RM., Basset-Seguin N., Bissonette R., Gerritsen MJ., Gilaberte Y., Calzavara-Pinton P., Morton CA., Sidoroff A., and Braathen LR., Daylight photodynamic therapy for actinic keratosis: an international consensus: International Society for Photodynamic Therapy in Dermatology., J Eur Acad Dermatol Venereol., 26, 6, 673, 679, 2012.

15 Wiegell SR., Fabricius S., Gniadecka M., Stender IM., Berne B., Kroon S., Andersen BL., Mork C., Sandberg C, Ibler KS., Jemec GB., Brocks KM., Philipsen PA., Heydenreich J., Haedersdal M., and Wulf HC., Daylight-mediated photodynamic therapy of moderate to thick actinic keratoses of the face and scalp: a randomized multicentre study., Br J Dermatol., 166, 6, 1327, 1332, 2012.

16 Rubel DM., Spelman L., Murrell DF., See JA., Hewitt D., Foley P., Bosc C., Kerob D., Kerrouche N., Wulf HC., and Shumack S., Daylight photodynamic therapy with methyl aminolevulinate cream as a convenient, similarly effective, nearly painless alternative to conventional photodynamic therapy in actinic keratosis treatment: a randomized controlled trial., Br J Dermatol., 171, 5, 1164, 1171, 2014.

17 Cantisani C., Paolino G., Pellacani G., Didona D., Scarno M., Faina V., Gobello T., and Calcieri S., MAL Daylight Photodynamic Therapy for Actinic Keratosis: Clinical and Imaging Evaluation by 3D Camera., Int J Mol Sci., 17, 7, 1108, 2016.

18 Vignion-Dewalle AS., Betrouni N., Tylcz JB., Vermandel M., Mortier L., and Mordon S., Comparison of three light doses in the photodynamic treatment of actinic keratosis using mathematical modeling., J Biomed Opt., 20, 5, 58001, 2015.

19 Vignion-Dewalle AS., Baert G., Devos L., Thecua E., Vicentini C., Mortier L., and Mordon S., Red light photodynamic therapy for actinic keratosis using $37 \mathrm{~J} / \mathrm{cm}^{2}$ : fractionated irradiation with $12.3 \mathrm{~mW} / \mathrm{cm}^{2}$ after 30 minutes incubation time compared to standard continuous irradiation with $75 \mathrm{~mW} / \mathrm{cm}^{2}$ after three hours incubation time using a mathematical modeling., Lasers in Surgery and Medicine, Pending publication, 2017.

20 GALDERMA, Aktilite tailored for PDT, http://www.galderma.se/Portals/3/images/2014/files/Brochure\%204p_AKTILITE_201 303.pdf, 2013.

21 Moseley H., Light distribution and calibration of commercial PDT LED arrays., Photochem Photobiol Sci., 4, 11, 911, 914, 2005. 
22 Calzavara-Pinton PG., Venturini M., Sala R., Capezzerra R., Parrinello G., Specchia C., and Zane C., Methylaminolaevulinate-based photodynamic therapy of Bowen's disease and squamous cell carcinoma., Br J Dermatol., 159, 1, 137, 144, 2008.

23 Szeimies RM., Ibbotson S., Murrell DF., Rubel D., Frambach Y., De Berker D., Dummer R., Kerrouche N., and Villemagne H., A clinical study comparing methyl aminolevulinate photodynamic therapy and surgery in small superficial basal cell carcinoma (8-20 mm), with a 12-month follow-up., J Eur Acad Dermatol Venereol., 22, 11, 1302, 1311, 2008.

24 Lee JW., Kim BJ., and Kim MN., Photodynamic therapy: new treatment for recalcitrant Malassezia folliculitis., Lasers Surg Med., 42, 2, 192, 196, 2010.

25 Kim ST., Kang DY., Kang JS., Baek JW., Jean YS., and Suh KS., Photodynamic therapy with methyl-aminolaevulinic acid for mycosis fungoides., Acta Derm Venereol., 92, 3, 264, 268, 2012.

26 Kim SK., Park JY., Song HS., Kim YS., and Kim YC., Photodynamic therapy with ablative carbon dioxide fractional laser for treating Bowen disease., Ann Dermatol, 25, 3, 335, 339, 2013.

27 Fernandez-Guarino M., Harto A., Perez-Garcia B., Royuela A., and Jaen P., Six Years of Experience in Photodynamic Therapy for Basal Cell Carcinoma: Results and Fluorescence Diagnosis from 191 Lesions., J Skin Cancer, 2014, 849248, 2014.

28 Szeimies RM., Karrer S., Radakovic-Fijan S., Tanew A., Calzavara-Pinton P., Zane C., Sidoroff A., Hempel M., Ulrich J., Proebstle T., Meffert H., Mulder M., Salomon D., Dittmar HC., Bauer JW., Kernland K., and Braathen L., Photodynamic therapy using topical methyl 5-aminolevulinate compared with cryotherapy for actinic keratosis: A prospective, randomized study., J Am Acad Dermatol., 47, 2, 258, 262, 2002.

29 Pariser D., Loss R., Jarratt M., Abramovits W., Spencer J., Geronemus R., Bailin P., and Bruce S., Topical methyl-aminolevulinate photodynamic therapy using red lightemitting diode light for treatment of multiple actinic keratoses: A randomized, doubleblind, placebo-controlled study., J Am Acad Dermatol., 59, 4, 569, 576, 2008.

30 Szeimies RM., Matheson RT., Davis SA., Bhatia AC., Frambach Y., Klövekorn W., Fesq H., Berking C., Reifenberger J., and Thaçi D., Topical methyl aminolevulinate photodynamic therapy using red light-emitting diode light for multiple actinic keratoses: a randomized study., Dermatol Surg, 35, 4, 586, 892, 2009.

31 Wiegell SR., Fabricius S., Heydenreich J., Enk CD., Rosso S., Bäumler W., Baldursson BT., and Wulf HC., Weather conditions and daylight-mediated photodynamic therapy: protoporphyrin IX-weighted daylight doses measured in six geographical locations., Br J Dermatol., 168, 1, 186, 191, 2013.

32 Lane KL., Hovenic W., Ball K., and Zachary CB., Daylight photodynamic therapy: the Southern California experience., Lasers Surg Med., 47, 2, 168, 172, 2015. 
33 Perez-Perez L., Garcia-Gavin J., and Gilaberte Y., Daylight-mediated photodynamic therapy in Spain: advantages and disadvantages., Actas Dermosifiliogr., 105, 7, 663, 674, 2014.

34 See JA., Shumack S., Murrell DF., Rubel DM., Fernandez-Penas P., Salmon R, Hewitt D., Foley P., and Spelman L., Consensus recommendations on the use of daylight photodynamic therapy with methyl aminolevulinate cream for actinic keratoses in Australia., Australas J Dermatol., 57, 3, 167, 174, 2015.

35 Mordon S., A commentary on the role of skin temperature on the effectiveness of ALA-PDT in dermatology., Photodiagnosis Photodyn Ther., 11, 3, 416, 419, 2014.

36 Liu B, Farrell TJ, and Patterson MS, A dynamic model for ALA-PDT of skin: simulation of temporal and spatial distributions of ground-state oxygen, photosensitizer and singlet oxygen, Physics in Medicine and Biology, 55, 5912, 5932, 2010 .

37 Garcia-Uribe A., Zou J., Duvic M., Cho-Vega JH., Prieto VG., and Wang LV., In vivo diagnosis of melanoma and nonmelanoma skin cancer using oblique incidence diffuse reflectance spectrometry., Cancer Res., 72, 11, 2738, 2745, 2012.

38 Spelman L., Rubel D., Murrell DF., See JA., Hewitt D., Foley P., Salmon R., Kerob D., Pascual T., Shumack S., and Fernandez-Penas P., Treatment of face and scalp solar (actinic) keratosis with daylight-mediated photodynamic therapy is possible throughout the year in Australia: Evidence from a clinical and meteorological study., Australas J Dermatol., 57, 1, 24, 28, 2016.

39 O'Gorman SM., Clowry J., Manley M., McCavana J., Gray L., Kavanagh A., Lally A., and Collins P., Artificial White Light vs Daylight Photodynamic Therapy for Actinic Keratoses: A Randomized Clinical Trial., JAMA Dermatol., 152, 6, 638, 644, 2016.

40 Farrell TJ., Hawkes RP., Patterson MS., and Wilson BC., Modeling of photosensitizer fluorescence emission and photobleaching for photodynamic therapy dosimetry., Appl Opt., 37, 31, 7169, 7183, 1998.

41 Valentine RM., Brown CT., Moseley H., Ibbotson S., and Wood K., Monte Carlo modeling of in vivo protoporphyrin IX fluorescence and singlet oxygen production during photodynamic therapy for patients presenting with superficial basal cell carcinomas., J Biomed Opt., 16, 4, 048002, 2011.

42 Vignion-Dewalle AS., Baert G., Thecua E., Vicentini C., Mortier L., and Mordon S., A software for analyzing and comparing the light sources available for PDT in dermatology., 16th Annual Congress of the European Society for Photodynamic Therapy (EURO-PDT), Munich, 2017.

43 Christiansen K., Bjerring P., and Troilius A., 5-ALA for photodynamic photorejuvenation--optimization of treatment regime based on normal-skin fluorescence measurements., Lasers in Surgery and Medicine, 39, 4, 302, 310, 2007.

44 Lerche CM., Heerfordt IM., Heydenreich J., and Wulf HC., Alternatives to Outdoor Daylight Illumination for Photodynamic Therapy--Use of Greenhouses and Artificial Light Sources., Int J Mol Sci., 17, 3, 309, 2016. 